\title{
R337H mutation of the TP53 gene as a clinical marker in cancer patients: a systematic review of literature
}

\author{
L.M. Borges ${ }^{1,2}$ and F.M. Ayres ${ }^{2,3}$ \\ ${ }^{1}$ Hospital das Clínicas, Universidade Federal de Goiás, Goiânia, GO, Brasil \\ ${ }^{2}$ Mestrado em Genética, Pontifícia Universidade Católica de Goiás, Goiânia, GO, \\ Brasil \\ ${ }^{3}$ Laboratório de Pesquisa em Genética, Campus Goiânia, \\ Universidade Estadual de Goiás, Goiânia, GO, Brasil \\ Corresponding author: F.M. Ayres \\ E-mail: flavioayres@yahoo.com
}

Genet. Mol. Res. 14 (4): 17034-17043 (2015)

Received August 7, 2015

Accepted October 11, 2015

Published December 16, 2015

DOI http://dx.doi.org/10.4238/2015.December.16.4

ABSTRACT. The germline R337H mutation of the TP53 gene has been associated with the development of many tumor types. This systematic review of literature investigated the association between the $\mathrm{R} 337 \mathrm{H}$ mutation and the patients' family history and its predictive and prognostic value in cancer. Data were collected from articles archived in the PubMed, LILACS, MEDLINE, IBECS, and SciELO databases. The systematic review of literature was performed on 12 selected articles, describing a total of 175,462 individuals tested for the R337 H mutation, including 1548 individuals with cancer and 118 individuals with a family history of Li-Fraumeni and LiFraumeni-like syndrome. Eight studies showed an association between the mutation and a family history of cancer in 411 patients, including 390 cases of cancer among family members. Patients with the homozygous mutant genotype experienced cancer recurrence, progressive disease, secondary cancer, and a short survival rate. Heterozygous patients showed a better response to treatment and increased survival rates than did patients with 
the homozygous mutant genotype from newborns to adult patients. In conclusion, the $\mathrm{R} 337 \mathrm{H}$ mutation has significant predictive and prognostic value and is associated with tumorigenesis of the adrenal cortex.

Key words: Adrenocortical carcinoma; Founder effect; Prognosis; Missense mutation; p.R337H

\section{INTRODUCTION}

Deregulation of the TP53 pathway is important in the pathogenesis of human cancer because p53 regulates the transcription of genes involved in the cell cycle, DNA repair, apoptosis, signaling, transcription, and metabolism. Furthermore, p53 acts on independent transcription pathways that induce apoptosis and cytoplasmic autophagy (Xu-Monette et al., 2012). In Brazil, a germline mutation established by the exchange of the amino acid arginine for histidine at codon 337 (R337H CGC $\rightarrow$ CAC) has been correlated with tumorigenesis (Olivier et al., 2010), although its range of tumors remains unclear (Seidinger et al., 2011).

The $\mathrm{R} 337 \mathrm{H}$ allele encodes a protein with a conservative mutation at the C-terminal domain. The histidine at the position 337 does not act as an intermolecular hydrogen bond donor when the cellular environment is alkaline and at high temperatures. Such a protonation change, due to the replacement of arginine by histidine, affects the salt bridge with amino acid 352, producing unstable p53 tetramers and eventually resulting in a loss of function (DiGiammarino et al., 2002).

The association between the mutation, the emergence of different tumor types, and the high number of carriers make the $\mathrm{R} 337 \mathrm{H}$ mutation an important factor in public health, particularly in predicting cancer (Achatz, 2008; Palmero et al., 2008; Achatz et al., 2009). The incidence of cancer at an early age resulting from the $\mathrm{R} 337 \mathrm{H}$ mutation represents up to $5 \%$ of all cancers before the age of 70 and $5-10 \%$ of all cancers in children and young adults in southern Brazil. Mutation carriers have a significant risk of developing multiple cancers (Achatz, 2008).

In order to investigate the role of the TP53 R337H mutation as a clinical marker in cancer patients, we studied the association between the mutation and patients' family history, its predictive value in cancer, and its prognostic value in cancer.

\section{MATERIAL AND METHODS}

This study was a systematic (SRL) and descriptive review of literature of data examining the $\mathrm{R} 337 \mathrm{H}$ mutation in the TP53 gene. The requirements established by the Cochrane Collaboration were fulfilled during reference identification and selection. Data were collected between January and September in 2013 using the following electronic databases: PubMed, LILACS, MEDLINE, IBECS, and SciELO. The descriptors used in the search were selected through Health Sciences Descriptors: adrenocortical carcinoma, founder effect, and TP53 missense mutation. We also used similar descriptors in Portuguese and Spanish. We searched for the following terms and their synonyms in Portuguese and Spanish in order to broaden the search: "adrenocortical", "effect", "founder", "TP53", "mutation”, "p.R337H”, and "R337H”.

We included in the study: a) primary studies and descriptors related to the $\mathrm{R} 337 \mathrm{H}$ mutation of the TP53 gene and its potential as a clinical prognostic marker in cancer patients with the mutation; b) data published between 1997 and September 2013, available in English, Portuguese, or Spanish; c) scientific articles available in national and international journals. Articles that were 
only partially available were excluded from analysis.

The criteria established by the test of relevance I (applied to references and abstracts) and test of relevance II (applied by 2 reviewers for qualitative analysis) were used for study selection. The reviewers answered the questions affirmatively or negatively. Any articles evaluated as negative were excluded from the SRL. Data were independently extracted in a detailed manner from articles selected using the test of relevance II. The tests of relevance and the protocol for data extraction were adapted from Pereira and Bachion (2006) and Azevedo (2010). The strength of evidence adopted by Hicks (2004) was applied.

In order to analyze allele and genotype frequencies, we analyzed whether the populations were in Hardy-Weinberg equilibrium. The $x^{2}$ test was performed to determine whether the differences between observed and expected numbers of each genotype were random. We performed calculations to determine the validity of the diagnostic tests to associate the predictive value with the R337H mutation (Pereira and Andrade, 1997). Proportions/rates regarding sensitivity, specificity, prevalence, estimated prevalence, positive predictive value (PPV), and negative predictive value (NPV) were calculated using the data extracted from the selected studies.

\section{RESULTS}

Ninety-seven publications were identified in 4 databases, including PubMed, MEDLINE, LILACS, and Scielo with 47, 41, 5, and 4 articles, respectively. Repeated studies $(\mathrm{N}=58)$ from databases were considered only once. One article found in PubMed database was excluded because it was not fully available. Therefore, 39 articles (40.2\%) were screened for the test of relevance I.

After applying the relevance test, 21 (53.8\%) articles were excluded from the study because they were not related to the subject, were not published during the stipulated period, were in a different language, were not primary studies, or did not address a solution for the problem investigated. Hence, 18 (46.1\%) articles were selected for the test of relevance II. After applying the test of relevance II, 6 articles were excluded because they were unrelated to the study topic, the methodology was not clearly described, or the objectives or results were inconsistent with the methodology presented. Data extraction and the SRL were performed for 12 articles (Figure 1).

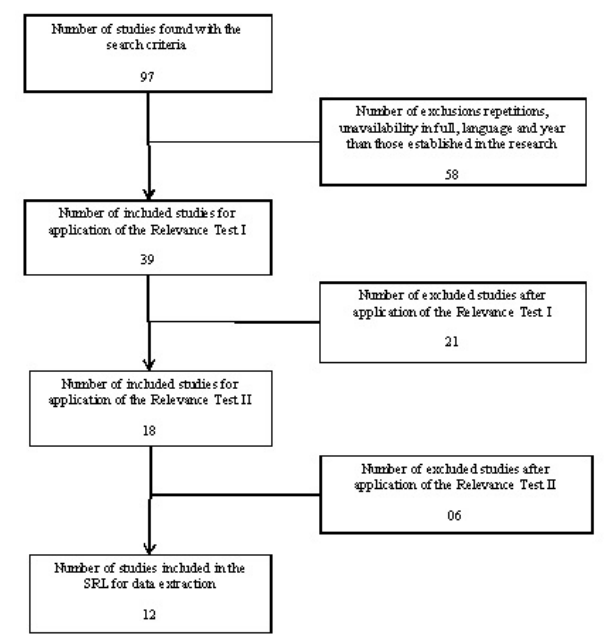

Figure 1. Flowchart of included and excluded studies. 
The studies included in this SRL are shown in Table 1. Eleven of the 12 studies included individuals from southern and southeastern Brazil, while 1 study was a case study of a homozygous individual in Germany. The 12 selected articles included 1548 individuals with cancer, including adrenal cortex tumor (ACT), kidney and breast cancer, choroid plexus carcinoma, choroid plexus papilloma, soft tissue sarcoma, synovial sarcoma of leg and osteosarcoma, and other types of cancer (Figure 2). Family history of Li-Fraumeni and Li-Fraumeni like syndrome was reported in 118 individuals.

\begin{tabular}{|c|c|c|c|c|}
\hline Title & Main author & Location & Periodic & Year \\
\hline $\begin{array}{l}\text { Penetrance of adrenocortical tumors } \\
\text { associated with the germlineTP } 53 \mathrm{R} 337 \mathrm{H} \text { mutation }\end{array}$ & Figueiredo BC & Paraná, Brazil & J. Med. Genet. & 2006 \\
\hline $\begin{array}{l}\text { The TP53 mutation, R337H, is associated with } \\
\text { Li-Fraumeni and Li-Fraumeni-like syndromes } \\
\text { in Brazilian families }\end{array}$ & Achatz MI & São Paulo, Brazil & Cancer Lett. & 2007 \\
\hline $\begin{array}{l}\text { Detection of R337H, a germline TP53 mutation } \\
\text { predisposing to multiple cancers, in asymptomatic } \\
\text { women participating in a breast cancer screening } \\
\text { program in Southern Brazil }\end{array}$ & Palmero El & Porto Alegre, Brazil & Cancer Lett. & 2008 \\
\hline $\begin{array}{l}\text { Association of the germlineTP53 R337H mutation } \\
\text { with breast cancer in southern Brazil }\end{array}$ & Assumpção JG & Campinas, Brazil & BMC & 2008 \\
\hline $\begin{array}{l}\text { Increased incidence of choroid plexus carcinoma } \\
\text { due to the germlineTP53 R337H mutation in } \\
\text { southern Brazil }\end{array}$ & Custodio G & Curitiba, Brazil & Plos One & 2011 \\
\hline $\begin{array}{l}\text { Association of the highly prevalent TP53 } \\
\text { R337H mutation with pediatric choroid plexus } \\
\text { carcinoma and osteosarcoma in southern Brazil }\end{array}$ & Seidinger AL & Campinas, Brasil & Cancer & 2011 \\
\hline $\begin{array}{l}\text { TP53 germline mutation in adult patients with } \\
\text { adrenocortical carcinoma }\end{array}$ & Herrmann LJM & Munique, Germany & $\begin{array}{l}\text { J. Clin. Endocrinol. } \\
\text { Metab. }\end{array}$ & 2012 \\
\hline The R337H mutation in TP53 and breast cancer in Brazil & Gomes MCB & Rio de Janeiro, Brasil & HCCP Journal & 2012 \\
\hline Number of rare germline CNVs and TP53 mutation types & Silva AG & São Paulo, Brasil & $\begin{array}{l}\text { Orphanet Journal } \\
\text { of Rare Diseases }\end{array}$ & 2012 \\
\hline $\begin{array}{l}\text { Impact of neonatal screening and surveillance for the } \\
\text { TP53 R337H mutation on early detection of childhood } \\
\text { adrenocortical tumors }\end{array}$ & Custódio G & Paraná, Brazil & J. Clin. Oncol. & 2013 \\
\hline $\begin{array}{l}\text { A TP53 founder mutation, } p . R 337 \mathrm{H} \text {, is associated } \\
\text { with phyllodes breast tumors in Brazil }\end{array}$ & Giacomazzi J & $\begin{array}{l}\text { Porto Alegre and } \\
\text { Barretos, Brazil }\end{array}$ & Vichows Arch. & 2013 \\
\hline $\begin{array}{l}\text { Spindle assembly checkpoint gene expression in } \\
\text { childhood adrenocortical tumors (ACT): } \\
\text { overexpression of aurora kinases A and B is } \\
\text { associated with a poor prognosis }\end{array}$ & Borges KS & Ribeirão Preto, Brazil & Pediatr. Blood Cancer & 2013 \\
\hline
\end{tabular}

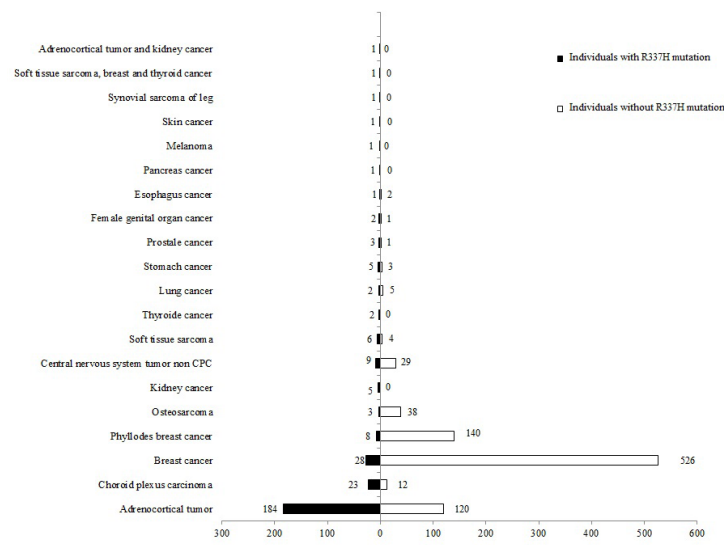

Figure 2. Tumors reported in the studies included. 
We included 750 healthy women who took part in a fight against breast cancer group, 647 control patients, and 171,649 newborns; 19 of these newborns were included in the group of cancer patients because they were diagnosed with ACT (Figure 2). The total number of individuals included in the SRL analysis for the R337H mutation was 175,462 .

The frequency of the $\mathrm{R} 337 \mathrm{H}$ mutation of the TP53 gene in Brazil is significantly higher than in other countries. Among the subjects included in the SRL, 175,359 were Brazilian (99.9\%) and 103 were German (0.1\%). Regarding patients with cancer $(\mathrm{N}=287)$ and those with the $\mathrm{R} 337 \mathrm{H}$ mutation, including 19 newborns with ACT, 1 was German and the others Brazilians. Figure 2 shows the types of cancer found in patients who had the mutation and Figure 3 shows healthy individuals who carried the $\mathrm{R} 337 \mathrm{H}$ mutation.

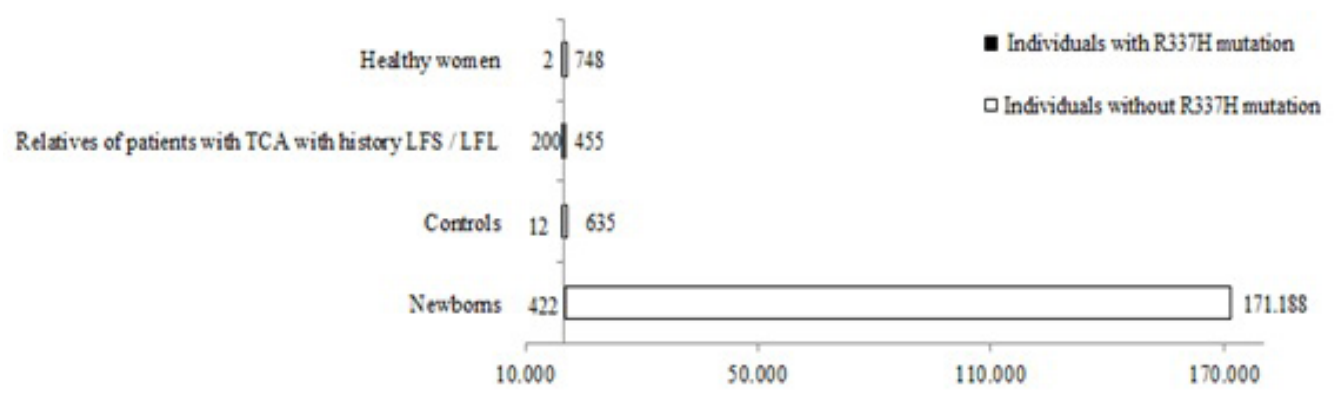

Figure 3. Data of the individuals considered healthy in the studies included.

Eight studies associated the R337H mutation with a family history of cancer in 411 patients, including 390 cases of cancer among family members. Figure 4 shows the types of cancer found in relatives of individuals with the $\mathrm{R} 337 \mathrm{H}$ mutation.

The average allele frequency of the wild-type allele $(R)$ was 0.89 and of the mutant allele $(H)$ was 0.11 . The average genotype frequencies were $0.70(R R), 0.21(R H)$, and $0.001667(H H)$. The standard deviation of the allelic frequency for both the wild-type and the mutant allele was 0.13 . For the genotype frequencies, standard deviations were 0.26 (RR and HR) and 0.003727 $(\mathrm{HH})$. The RR genotype was found in a total of 174,695 individuals, the HR genotype in 935 individuals, and the $\mathrm{HH}$ genotype in 8 individuals. Comparing the observed and the expected genotype frequencies, there were more heterozygous $\mathrm{HR}$ and homozygous $\mathrm{HH}$ in the population than expected. However, the deviation between the expected and the observed values for individuals with and without the $\mathrm{R} 337 \mathrm{H}$ mutation was likely less than $2.5 \%$, which may be considered random variability ( $P$ values ranged from $0.00001149-0.40209424)$.

The sensitivity, specificity, prevalence, estimated prevalence, PPV, and NPV were calculated in order to analyze the association between the $\mathrm{R} 337 \mathrm{H}$ mutation and its predictive value. The calculations were based on all cases or on each group of patients separately to test the reliability of information. Newborns diagnosed with ACT were aged 3-112 months. Therefore, the group of newborns was excluded from some of the calculations because these individuals were too young to develop some of the tumors associated with the R337H mutation. In contrast, the R337H mutation may be related to tumor development at any age of a patient's lifetime. The ranges of the values for the rates/indicators were: sensitivity $0.05405405-1$, specificity $0.90630473-0.99622802$, prevalence 0.00001149-0.40209424, estimated prevalence 0.00377766-0.15378671, PPV 0.050450451, and NPV 0.62368183-1. Sensitivity, PPV, and NPV values were equal to 1 because of the small number of cases for the type of tumor studied, particularly for soft tissue sarcoma, melanoma, 
pancreatic cancer, skin cancer, kidney cancer, thyroid cancer, synovial sarcoma of leg, and multiple tumors (ACT and kidney or thyroid, breast cancer, and soft tissue sarcoma).

A total of 64 patients with cancer were analyzed for the association between the R337H mutation and prognosis. These subjects were aged 3 months to 71 years, and their tumors included: carcinoma of the adrenal cortex (3/64), ACT (52/64), or choroid plexus carcinoma (9/64). The prognosis in homozygous patients for the mutation was worse than that in heterozygous patients. A high number of patients with the homozygous mutant genotype experienced cancer recurrence, progressive disease, secondary cancer, and a short survival time. Heterozygous patients showed a better response to treatment and increased survival times compared to patients with the homozygous mutant genotype.

This SRL was classified as level V of evidence because we used opinions of respected authorities, clinical evidence, and descriptive studies or reports of expert committees and conducted evaluation according to the strength of evidence of the included studies.

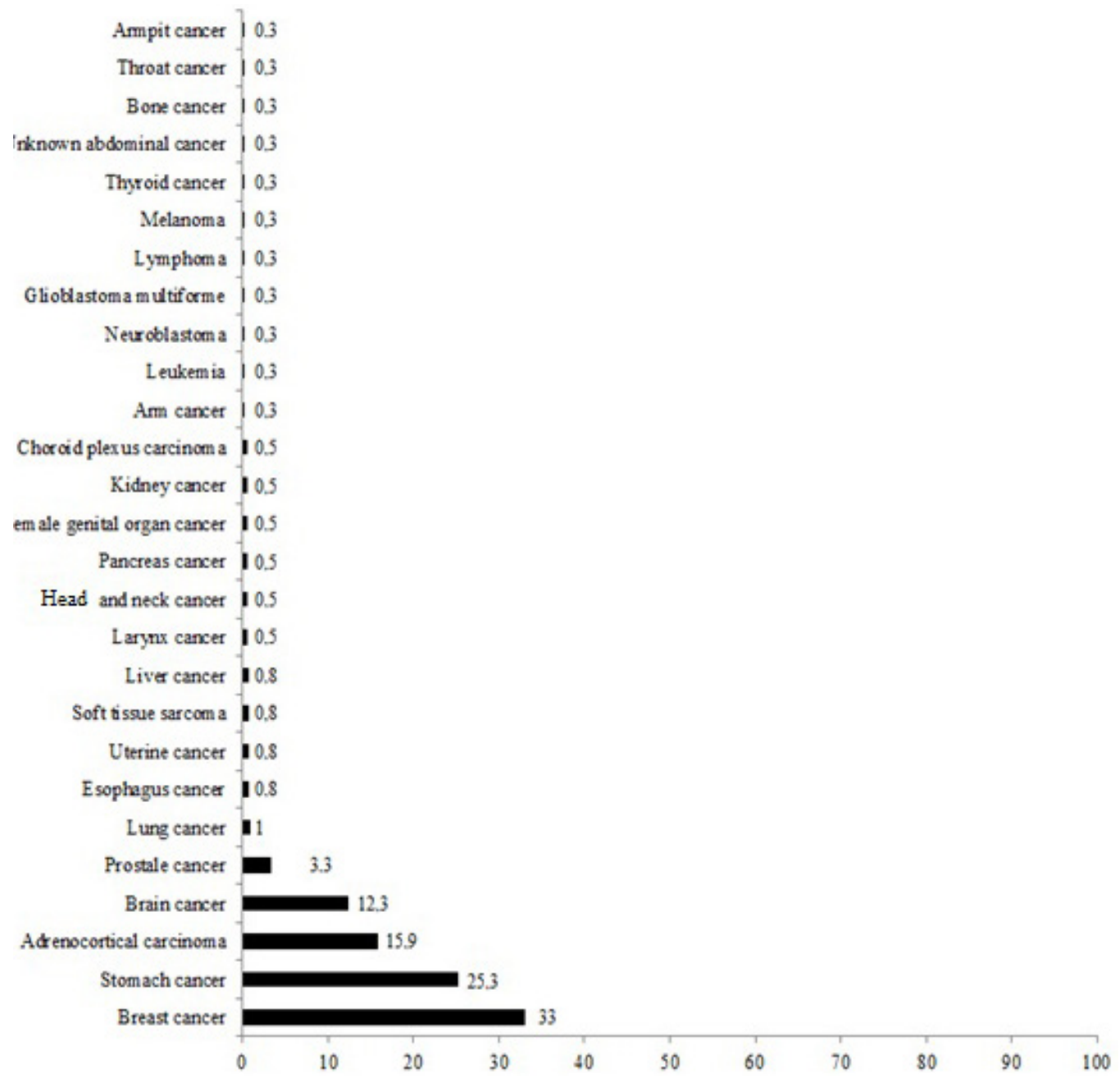

Figure 4. Tumors reported in the relatives of individuals with the R337H mutation (\%). 


\section{DISCUSSION}

Since the R337H mutation was initially identified in Paraná and São Paulo States, numerous studies have been conducted to determine the origin and the role of this mutation in carcinogenesis. The $\mathrm{R} 337 \mathrm{H}$ mutation was recently identified in children with choroid plexus carcinoma and osteosarcoma from Minas Gerais State, showing that the mutation is not restricted to São Paulo and Paraná States (Seidinger et al., 2011). However, the R337H mutation was not identified in children with ACT from the Northeast region of Brazil (Pereira, 2006). This difference in the genotypes of ACT patients may have been observed because the population investigated in the Northeast was not related to subjects in the Southern Brazil or because of ethnic differences.

The first carrier of the R337H mutation identified outside of Brazil was in France (Bougeard et al., 2001). An active search was also carried out in the 3 main Portuguese Centers of Oncogenetics, but no mutation carrier was found (Achatz, 2008). Recently, a study conducted in Germany found a patient carrier of the $\mathrm{R} 337 \mathrm{H}$ mutation diagnosed with adrenocortical carcinoma. The mutation was detected both in peripheral blood and tumor tissue. The patient was also diagnosed with prostate cancer and colon cancer and had a family history of cancer. The patient's father was diagnosed with prostate cancer and the daughter with breast cancer; however, neither of these family members were genotyped. Analysis of SNP179 in the German patient revealed a distinct haplotype from that described in Brazil, indicating independent occurrence of the germline mutation (Herrmann et al., 2012).

In the present SRL, most studies showed an association between family histories of cancer of the patients and the R337H mutation. However, some tumors types found among the relatives could not be directly related to the $\mathrm{R} 337 \mathrm{H}$ mutation because of external factors, such as lung cancer caused by smoking. Additionally, the estimated penetrance of the mutant allele was approximately 10\% (Figueiredo et al, 2006; Wasserman et al, 2012). Although the mutation was found in nearly $100 \%$ of cases of ACT (Ribeiro et al., 2001), its frequency in the general population outside South and Southeast Brazil was low (Pianovski et al., 2006).

When the disease is rare, PPV is low because most of the positive tests were observed in healthy patients, leading to false-positive results. Furthermore, NPV is markedly higher for lowprevalence diseases (Pereira and Andrade, 1997). This variation in PPV and NPV was observed when we individually analyzed each type of tumor and changed when newborns were included or not. Tumors showing a higher prevalence of disease showed increased NPV and decreased PPV.

Late diagnosis may be an aggravating factor for the prognosis of patients with the R337H mutation. From $90-95 \%$ of children with ACT may be cured if screening of newborns and relatives was performed along with subsequent patient surveillance. The homozygous R337H mutant associated with other rare mutations in the TP53 gene or even in the wild-type gene may be associated with some cases of ACT. No screening and no surveillance result in the survival of approximately $50 \%$ of children with ACT, and these children may require toxic intensive chemotherapy (Custodio et al., 2011).

This SRL supports an association between the R337H genotype and the prognosis of cancer patients, where homozygous patients for the mutation had a worse prognosis than did heterozygous patients. Most homozygous patients developed more aggressive disease and had a shorter survival time. Heterozygous patients showed higher survival rates; however, they experienced disease recurrence or developed secondary tumors. Because some patients were still undergoing treatment, outcome evaluations were not fully reported.

Other types of tumors can occur with an increased frequency in R337H carriers, such as choroid plexus carcinoma, gastric and colon cancer, thyroid cancer, osteosarcoma, and breast 
cancer, among others (Latronico et al., 2001; Assumpção et al., 2008; Custodio et al., 2011; Seidinger et al., 2011; Seidinger et al., 2011; Gomes et al., 2012). Therefore, the deleterious action of the $\mathrm{R} 337 \mathrm{H}$ mutation cannot be limited to a single age group because tumors related to the mutation can affect a broad range of life stages, from newborns to adult patients.

Among patients with the R337H mutation included in the present study, most were diagnosed with $\mathrm{ACT}$, confirming an association between the mutation and this specific tumor type. Strong evidence indicates that the mutation is related to the tumorigenesis process in the adrenal cortex. Moreover, it is important to consider the following: 1) the mutation is not a frequent variant in the entire Brazilian population; 2) loss of heterozygosity leads to retention of the mutated allele in tumor cells; and 3) ACT cells may show increased expression of mutated p53 (Pereira, 2006).

The germline R337H mutation was found in patients with different tumors and its loss of heterozygosity was demonstrated in breast cancer (Achatz et al., 2007). From a clinical standpoint, detection of the R337H mutation in heterozygous patients from families with a wide range of hereditary tumors, consistent with the Li-Fraumeni and Li-Fraumeni like syndrome, indicates that this mutation has the potential to predispose to tumors in a variety of tissues, not in a specific tissue as was originally suggested (Ribeiro et al., 2001; Hainaut, 2002; Achatz et al., 2007).

Previous studies have demonstrated that patients with $\mathrm{R} 337 \mathrm{H}$ share a common set of alleles in adjacent polymorphic markers. This strongly indicates co-segregation between these markers and the R337H germline mutation. Additionally, the mutation may have originated from the founder effect in a common ancestor of most Brazilian patients with ACT (Pinto et al., 2004; Palmero et al., 2008). Analysis of inheritance patterns of families in Paraná State suggested that the R337H mutant allele emerged at least 110 years ago (Figueiredo et. al., 2006). Thus, the mutation likely emerged approximately 118 years ago.

Because of the high incidence and low survival of patients with adrenocortical tumors in Paraná State, the Bill No. 268/2008 was signed, which made the examination of DNA to detect the $\mathrm{R} 337 \mathrm{H}$ mutation mandatory in all newborns. The tests help prevent public expenditure related to the treatment of tumors in newborns at an advanced stage.

Studies included in the SRL, which included different cohorts, showed that the R337H germline mutation occurs in many types of cancer; however, none of the studies investigated constitutive genetic changes associated with the R337H mutation. Carriers of the R337H mutation showed different outcomes (childhood cancer, cancer in adulthood, one or multiple tumors, no tumor) in such a way that it was a major clinical challenge to predict the phenotype of R337H mutation carriers. There may be genetic factors acting as modifiers of penetrance and consequently the phenotype associated with the mutation. Genomic analysis are useful for initial screening to further investigate potentially related genetic load that could lead to cancer.

Given the relevance of the $\mathrm{R} 337 \mathrm{H}$ mutation in the epidemiological context of cancer in Brazil, additional studies are needed to examine the association between this mutation and related tumor types. The tracking of this mutation in different populations has allowed the implementation of policies and clinical protocols specific to patients who carry the mutation. Thus, the identification of at-risk patients is crucial for directing early clinical diagnosis of cancer and for improving treatment. The high incidence of the R337H mutation and its association with certain types of tumors indicate that this mutation should be investigated as a potential biomarker for tumor development risk.

Therefore, the R337H mutation of the TP53 gene has significant predictive value when correlated with potential clinical markers and can be used to estimate the risk and prognosis of cancer. This would positively contribute to the clinical management of individuals carrying the mutation, as the $\mathrm{R} 337 \mathrm{H}$ mutation in the TP53 gene is considered to be a current public health issue. 


\section{Conflicts of interest}

The authors declare no conflict of interest.

\section{ACKNOWLEDGMENTS}

Research supported by Fundação de Amparo à Pesquisa do Estado de Goiás (FAPEG), \#201201268940872). F.M. Ayres gratefully acknowledges the research fellowship granted from Universidade Estadual de Goiás (Programa de Incentivo à Pesquisa e Produção Científica, PROBIP). We also thank Professor Flávia Melo Rodrigues and Professor Tânia Cristina Dias da Silva Hamú for valuable discussions.

\section{REFERENCES}

Achatz MI (2008). Modificadores de penetrância de mutações germinativas no gene TP53 em famílias brasileiras com diagnóstico clínico da síndrome de Li-Fraumeni e Li-Fraumenilike: impacto dos polimorfismos intragênicos do TP53 e de genes que regulam a atividade da p53. Tese Doctoral thesis. Faculdade de Medicina, Universidade de São Paulo, São Paulo.

Achatz MI, Olivier M, Le Calvez F, Martel-Planche G, et al. (2007). The TP53 mutation, R337H, is associated with Li-Fraumeni and Li-Fraumeni-like syndromes in Brazilian families. Cancer Lett. 245: 96-102.

Achatz MI, Hainaut P and Ashton-Prolla P (2009). Highly prevalent TP53 mutation predisposing to many cancers in the Brazilian population: a case for newborn screening? Lancet Oncol. 10: 920-925.

Assumpção JG, Seidinger AL, Masterllaro MJ, Ribeiro RC, et al. (2008). Association of the germline TP53 R337H Mutation with breast cancer in Southern Brazil. BMC Cancer 8: 357.

Azevedo RS (2010). Sobrecarga do cuidador informal da pessoa idosa frágil: uma revisão sistemática. Master's thesis. Escola de Enfermagem, Universidade Federal de Minas Gerais, Belo Horizonte.

Bougeard G, Limacher JM, Martin C, Charbonnier F, et al. (2001). Detection of 11 germline inactivating TP53 mutations and absence of TP63 and HCHK2 mutations in 17 French families with Li-Fraumeni or Li-Fraumeni-like syndrome. J. Med. Genet. 38: 253-257.

Custódio G, Taques GR, Figueiredo BC, Gugelmin ES, et al. (2011). Increased incidence of choroid plexus carcinoma due to the germline TP53 R337H mutation in southern Brazil. PLoS One 6: e18015.

DiGiammarino EL, Lee AS, Cadwell C, Zhang W, et al. (2002). A novel mechanism of tumorigenesis involving pH-dependent destabilization of a mutant p53 tetramer. Nat. Struct. Biol. 9: 12-16.

Figueiredo BC, Sandrini R, Zambetti GP, Pereira RM, et al. (2006). Penetrance of adrenocortical tumours associated with the germline TP53 R337H mutation. J. Med. Genet. 43: 91-96.

Gomes MC, Kotsopoulos J, de Alemeida GL, Costa MM, et al. (2012). The R337H mutation in TP53 and breast cancer in Brazil. Hered. Cancer Clin. Pract. 10: 3.

Hainaut $\mathrm{P}$ (2002). Tumor-specific mutations in p53: the acid test. Nat. Med. 8: 21-3.

Herrmann LJ, Heinze B, Fassnacht B, Willenberg HS, et al. (2012). TP53 germline mutation in adult patients with adrenocortical carcinoma. J. Clin. Endocrinol. Metab. 97: E476-E485.

Hicks N (2004). Assessment criteria. Bandolier J. 39: 9.

Latronico AC, Pinto EM, Domenice S, Fragoso MC, et al. (2001). An inherited mutation outside the highly conserved DNAbinding domain of the p53 tumor suppressor protein in children and adults with sporadic adrenocortical tumors. J. Clin. Endocrinol. Metab. 86: 4970-4973.

Olivier M, Hollstein M and Hainaut P (2010). TP53 mutations in human cancers: origins, consequences, and clinical use. Cold Spring Harb. Perspect. Biol. 2: 01-08.

Palmero El, Schüler-Faccini L, Caleffi M, Achatz MI, et al. (2008). Detection of R337H, a germline TP53 mutation predisposing to multiple cancers, in asymptomatic women participating in a breast cancer screening program in Southern Brazil. Cancer Lett. 261: 21-25.

Pereira AL and Bachion MM (2006). Update in systematic literature revision review: strength criteria and degree of recommendation of literature evidences. Porto Alegre, Rev. Gaucha Enferm. 27: 491-498.

Pereira MG and Andrade AL (1997). Métodos de Investigação Epidemiológica em Doenças Transmissíveis. In: Avaliação de testes diagnósticos (Andrade ALSS and Zicker F, eds.). Fundação Nacional da Saúde / CENEPI/Ministério da Saúde e Organização Panamericana da Saúde, Brasília, 9-29. 
Pereira R (2006). Avaliação clínica e laboratorial de portadores da mutação TP53 R337H, parentes de pacientes portadores da mutação e com tumor do córtex adrenal na infância. Doctoral thesis. Faculdade de Medicina, Universidade Federal do Paraná, Curitiba.

Pianovski MA, Maluf EM, de Carvalho DS, Ribeiro R, et al. (2006). Mortality rate of adrenocortical tumors in children under 15 years of age in Curitiba, Brazil. Pediatr. Blood Cancer 47: 56-60.

Pinto EM, Billerbeck AE, Villares MC, Domenice S, et al. (2004). Founder effect for the highly prevalent R337H mutation of tumor suppressor p53 in Brazilian patients with adrenocortical tumors. Arg. Bras. Endocrinol. Metabol. 48: 647-650.

Ribeiro RC, Sandrini F, Figeuiredo B, Zambettig GP, et al. (2001). An inherited p53 mutation that contributes in a tissue-specific manner to pediatric adrenal cortical carcinoma. Proc. Natl. Acad. Sci. U. S. A. 98: 9330-9335.

Seidinger AL, Mastellaro MJ, Paschoal FF, Godoy Assumpção J, et al. (2011). Association of the highly prevalent TP53 R337H mutation with pediatric choroid plexus carcinoma and osteosarcoma in southeast Brazil. Cancer 117: 2228-2235.

Wasserman JD, Zambetti GP and Malkin D (2012). Towards an understanding of the role of p53 in adrenocortical carcinogenesis. Mol. Cell. Endocrinol. 351: 101-110.

Xu-Monette ZY, Medeiros LJ, Li Y, Orlowsky RZ, et al. (2012). Dysfunction of the TP53 tumor suppressor gene in lymphoid malignancies. Blood 119: 3668-3683. 